\title{
Assessing Challenges of Hospitality Sector in South Wollo Zone: The Case of Dessie and Kombolcha Towns
}

\author{
Zelalem Getnet \\ Wollo University, Department of Tourism and Hotel Management, Dessie, Ethiopia
}

\begin{abstract}
The principal purpose of this research is to examine challenges of hospitality sector in south Wollo zone of Kombolcha and Dessie Towns. The researcher employed mixed methodology. Data are collected from primary and secondary sources through questionnaire, interview, document review and personal observation to make the study more reliable and vibrant. The finding reveals that, the hotel industry is one of the fastest growth sectors in Dessie and Kombolcha towns. But, nearly $84.1 \%$ of hotels are not touristic hotels. Even most of the hotels except few could not be able to render quality services though the number of national and international tourists flow has been increasing from time to time. Regarding customer handling and level of customer satisfaction, $48.6 \%$ of respondents were strongly disagreed about the availability of good customer handling techniques in the sample hotels. The respondents also added that, except some hotels in Dessie and Kombolcha towns, most of them have critical problems of hygiene and sanitation. In general this study examines the difficulties faced by the hotel industry in the study area including the challenges faced by the tourists, workers as well culture and tourism industry. Hence, the regional government in collaboration with the zone culture and tourism department should invite more tourism investors to invest in the two towns particularly hotels investors and Problem related with hotel should solve promptly.
\end{abstract}

Keywords: Hospitality Sector, Dessie and Kombolcha Towns, Challenge

DOI: $10.7176 / \mathrm{JTHS} / 42-03$

Publication date:July $31^{\text {st }} 2019$

\section{Introduction}

There is no single and simple definition to explain the term of hospitality. Many people have tried to describe the hospitality industry in different ways. Broadly speaking, Hospitality is the act of kindness in welcoming and looking after the basic needs of customers or strangers, mainly in relation to food, drink and accommodation (Benny C.2013, John \& Sons, 2012).

It is a billion dollar industry and is a cluster of industries comprising of hotels, lodging, food services, recreation, entertainment, and travel sectors. The organizations offer comfort, entertainment and guidance to strangers (John Wiley \& Sons, 2012). On the other hand, tourism and hospitality industries are among the fast expanding industries in the world and show important growth and one of the top foreign earners for many countries, (Kenya Vision, 2013). Now days, in addition to agriculture and manufacturing industry, hospitality industries, of which tourism is one, is being considered as a key development alternatives to achieve the growth and transformation plan of Ethiopia. Due to the increasing numbers of visitors' flow from time to time, tourism industry is becoming the promissory service sectors in Ethiopia. Being a multi-sectored industry, tourism development is highly depends on hospitality industry, transportation industry, attractions or resources, and destination management sectors. Hospitality sectors such as hotels, restaurants, lodges, gust house etc have an important role for the successful and sustainable tourism development in particular and accelerating the growth of other economic and social activities in general( Ministry of Culture and Tourism ,2011). In many areas, hospitality sectors are also important attractions for foreign visitors/customers who bring them with high spending power than that of the locals and who tend to spend at a higher rate than they do when they are at home. This is also true in the case of domestic visitors/customers. Moreover, the needs or demands of customers/visitors for quality and authentic services and products from the hospitality sectors are increasing from time to time. Through the incomes from visitors/customers spending, service providers or hospitality sectors are often contribute significantly to the socio-economic development of an area directly and indirectly(Ebisa and Andualem,2013).

The hospitality industry is one of the fastest growth sectors of the global economies; its significant contribution is seen to be on an upward trend, as evidenced even here in Ethiopia where international hotel chains are opening its branches to reap the market rewards from this competitive industry. However compared to other African countries, the number of hotels in Ethiopia is smaller and in this regard Ethiopia has less competitiveness to attract big international conferences than other countries. In the regional states, the shortage of accommodation that meets international standards is quite serious problem (Ebisa and Andualem, 2013).

Amhara National Regional State, with Bahir Dar as the regional capital, is one of the nine regions in Ethiopia; located in the Northwestern part of the country. It has a total land area of $161,828.40$ square kilometers. Amhara region is divided into eleven administrative zones; each is further divided into "Woreda" (administrative 
community). The region is blessed with abundance and diversify natural and cultural heritages such as Rock hewn churches of Lalibela, the castle of Gondar, Semen Mountain National park, lake Tana monasteries and so on( Tourism Commission, 2005). In line with this, there are plethora hotels with different class particularly in the main tourist destination towns such as Gondar, Lalibela and Bahirdar. South Wollo Zone is one of the eleven administrative zones of the region, which comprises tremendous natural and cultural heritages however with very limited touristic hotels.

Since tourism destinations are spread throughout the country, infrastructure development connecting the sites, as well as hotel development, is necessary. In this regard the shortage of Hospitality sector in Komblcha and Dessie towns is one of the main impediments even to tourism development because complains are frequently being raised about the quality and variety of services and products of the hospitality sectors in these towns.

So as to solve this problem, conducting research and investigating the sources of its problem is indispensable. Therefore, the main objective of this research is to assess challenges of hospitality sectors in south Wollo zone of Kombolcha and Dessie towns.

The Specific Objectives of this research are

$>$ To examine the current status of tourist flows in south Wollo zone of Desse and Kombolcha towns.

$>$ To assess challenges of hotel industry in south Wollo zone of Desse and Kombolcha towns and to forward possible solution to the problems based on the research findings.

\section{Methodology \\ Description of the Study Area}

South Wollo Zone is one of the eleven administrative zones of the region, which is located in the central highland of Ethiopia. It borders North Wollo on the north, East Gojjam on the West, North Shewa on the south, and Afar region and Oromia Zone on the east (Discover Amhra, 2011). My study area Kombolcha and Dessie towns are situated in this zone. Dessie is situated $4001 \mathrm{~km}$ from Addis Ababa, the country capital city, which serve as the capital for the South Wollo Zone. It was founded as a town in 1893 by Negus Michael. The Dessie area is endowed plethora of natural and cultural heritages on the other hand Kombolch town is situated $25 \mathrm{~km}$ west Dessie.

\section{Study Design and Approaches}

This study is employ a mixed-methodology consisting of qualitative and quantitative tools, which helps to explore the experiences of international and national tourists as well as other host communities at the two South Wollo Zone towns towards the challenges of hospitality sector.

\section{Sample Size Determination}

Since, conducting a research by incorporating the whole population is unmanageable and costly; the researcher is used quota sampling techniques because Quota sampling is used when the population has different strata. Proportional or quota was allocation to kombolcha and Dessie towns; 65 respondents from each towns, and then finally employed random sampling technique to select the required 130 respondents from the two towns, and distributed closed ended questioners, and analyzed by using descriptive data analysis method.

\section{Data collection instruments}

The main data gathering instrument is closed-ended questionnaire that were distributed to randomly selected tourists, host communities' hotel customers and employees. Semi-structured interviews are used as one of the primary methods for data collection. Interview was held with key hospitality stakeholders such as hotel customers, owners, employees and culture and tourism officers. The researcher also collected secondary sources from published and unpublished sources such as official records of culture and tourism organizations, books, journals and reports and articles.

\section{Methods of Data Analysis}

To get detailed pictures of the challenges of hospitality sectors on the study area the content of the qualitative data was analyzed through descriptive and interpretative methods. Carefully gathered quantitative data was also processed in Statistical Package for Social Sciences (SPSS) Version 20.0. In the case of displaying the quantitative data, the researcher used tables and graph.

\section{Results and Discussion}

According to the official statistics of the Ministry of Culture and Tourism of the Federal Democratic Republic of Ethiopia (2003-2005), Ethiopia is experiencing an ever increasing international tourist flow with high arrival growth rate of $15.1 \%$ in $2002 / 03$ to $23.5 \%$ in $2004 / 05$. South Wollo zone is one of the tourism destinations of the country which is endowed with plethora of natural and cultural tourism resources. Both domestic and 
international tourists are visited the zone annually and the flow of domestic and international tourists that came and visited the various sites of the zone are listed in the following table.

Table No.1. Number of international and domestic tourists that visited South Wollo Zone (2000-2009 E.C)

\begin{tabular}{|l|l|l|l|l|l|l|l|l|l|l|l|l|}
\hline No & $\begin{array}{l}\text { Types of } \\
\text { tourist }\end{array}$ & 2,000 & 2,001 & 2,002 & 2,003 & 2,004 & 2,005 & 2,006 & 2,007 & 2,008 & 2,009 & Sub Total \\
\hline 1 & Domestic & & & & & & & & & & \\
& & 4,484 & & & & 420,324 & 639,755 & $1,549,153$ & 1049079 & 1228257 & $2,166,465$ & 2007158 \\
\hline 2 & International & 44 & 1 & & 1,288 & 4,949 & 4,916 & 2238 & $\mathbf{2 6 5 7}$ & 1,928 & 1,665 & 19,685 \\
\hline
\end{tabular}

Sources: South Wollo zone Culture and Tourism Department

As shown in the above table 9,064,675 domestic tourists visited the various tourist destinations of the zone from 2000 to 2009 i.e. since Ethiopian millennium to 2009. At the same time meager numbers of international tourists are visited these zone, 19,685 at the stated period. Thus, the flow of domestic tourist surpass by millions than international tourists. There are different factors for the variation of these numbers and the first and for most reason is that the number of pilgrimage tourist that came to Gishen Debre kerba which nearly more than half a million tourist influxes into the Zone. Even the number of the flow of international tourists has not increased rather there is high fluctuation. As observed in the above table the highest number of international tourists' recorded in the zone is in 2004 i.e 4,949. According to culture and tourism department data the lowest number of tourist recorded in 2000 which is 44 . Even though the quality and quantity tourism infrastructure is relatively increased from time in the zone the number of international tourists are decreased in 2009 E.C. the state of emergency that declared in the country might be the possible factor for the decreasing of foreign tourists. Of course, lack of promotion, using weak marketing strategy and lack of rewound international hotels are an impediment for the flow of international tourists in south Wollo zone.

\section{Challenges of hotel industry in Dessie and Kombolcha Towns}

Based on the sampling technique and procedure described so far, totally one hundred thirty questionnaires were distributed to the respondents of the study and only one hundred seven have been filled up properly. Accordingly, the following results are found.

When we see the demographic profile of the respondents, out of the 107 respondents $60.7 \%$ were male and the remaining $39.3 \%$ were women where as in terms of age composition majority of the respondents were between the age of $29-40$ (46.7\%) followed by $18-29(40.2 \%)$ and above $40(13.1 \%)$. This indicates that the number of males who are consuming in a hotel is much greater than their counter part.

Table No 2. Availability of standard hotel supply in Dessie town and South wollo Zone

\begin{tabular}{|l|l|c|}
\hline There is standard hotel supply for tourists in Dessie town and south Wollo zone & Frequency & Percent (\%) \\
\hline Strongly disagree & 90 & 84.1 \\
\hline Disagree & 8 & 7.5 \\
\hline Not sure & 7 & 6.5 \\
\hline Agree & 2 & 1.9 \\
\hline Total & 107 & 100.0 \\
\hline
\end{tabular}

Sours: the researcher's survey, 2017

As it can be seen from the above table $84.1 \%$ are strongly disagree about the availability of standard touristic hotel in both Dessie town and south Wollo zone and $6.5 \%$ of respondents also didn't believe there is enough amount of hotels in Dessie town and south wollo Zone however, only $1.9 \%$ of the respondents agreed that there are standard hotels in the stated sites. This indicate that there is shortage of standard touristic hotels in these area and have its own adverse effect towards the flow of international tourists, hence, both the zone and the town administration and culture tourism departments work in collaborate with other stakeholders so as to draw both international and national tourists by increasing the quality and quantity of touristic hotels.

When we observe the tendency of proper service delivery $33.6 \%$ were strongly disagree and $51.4 \%$ were disagree regarding the proper service delivery of hotels for international tourists. This indicate that even the existed hotels can't able to delivered services that international tourists. Except few, most of the hotels provide room rent, food and beverage services. However swimming pool, meeting room, gym, sauna bath and other related services that demanded by tourists are available only in three hotels. As it is asserted by Sulaiman, interviewed in September, 2017 and personal observation of the researcher, Sunny side hotel is the only hotel that provides swimming pool service for tourists and local communities too. Thus, the unavailability of such service reduced the flow of tourists in the study area. On the other hand a service that delivered for domestic tourists are worse than international tourists, $48.6 \%$ and $23.4 \%$ of the respondent strongly disagree and disagrees respectively regarding the service that delivered for domestic tourists are proper. This might be emanated that domestic tourists can`t complain like international tourists, on the other hand both hotel managers and waitress 
give high value and prestige for expatriates than domestic ones.

Another important question that forwarded for respondents is, is it the hotel managers, waitress and other workers are trained in hotel sector or not. And the respondents answer is described in the following table.

Table No.3. Hotel service provider educational and training capacity and status

\begin{tabular}{|l|l|l|}
\hline $\begin{array}{l}\text { Hotel workers such as managers, head of different hotel departments and waitress } \\
\text { have education and training in hotel management. }\end{array}$ & Frequency & $\begin{array}{l}\text { Percent } \\
(\%)\end{array}$ \\
\hline strongly disagree & 39 & 36.4 \\
\hline Disagree & 9 & 8.4 \\
\hline not sure & 8 & 7.5 \\
\hline Agree & 51 & 47.7 \\
\hline Total & 107 & 100.0 \\
\hline
\end{tabular}

Sours: the researcher's survey, 2016

As elucidated in the above table almost half of the respondents are strongly disagree and disagree whereas the remaining $47.7 \%$ were agreed that most of hotel managers and head of front office, food and beverage department and the like have education in hotel management. Unlike the respondents, the south wollo zone culture and tourism department report and my key informant shows almost all employee in sample hotels are not professional even key hotel positions are run by families of hotel owners and the remaining vacant are held by non professionals. Of course some big hotels prepare short term training to their employees in order to give insight about hotel industry and customer handling techniques. In line with this, respondents were asked about the status of customer handling in the sample hotels and $48.6 \%$ was strongly disagree that there is good customer handling whereas $5.6 \%$ were agreed that they received good customer handling in the sample hotels and the remaining $20.6 \%$ are not sure whether the hotels customer handling technique is satisfactory or not.

TableNo. 4. Hotel industry is flourishing in alarming rate at South Wollo zone and Dessie Town

\begin{tabular}{|l|l|l|}
\hline In South Wollo zone and Dessie Town hotel industry is flourishing & Frequency & Percent (\%) \\
\hline strongly disagree & 24 & 22.4 \\
\hline Disagree & 10 & 9.3 \\
\hline Not sure & 2 & 1.9 \\
\hline Agree & 71 & 66.4 \\
\hline Total & 107 & 100.0 \\
\hline
\end{tabular}

Sours: the researcher's survey, 2016

The result reveals that $66.4 \%$ of the respondents were agreed that hotel investment is growing in both sites. My informants, Souliman and Temesgen also asserted that some of the standard hotels that exist in Dessie town have joined the hotel industry in the last one and two years and the trend are going to continue.

Other problems that frequently seen in this study area hotels are:

Infrastructure problems: Besides, there were electric power interruptions frequently which some of the respondents considered as major problem. Further, there were poor internet and other communication connections in both sites and these became hindering factor for hotels to provide excellent services.

\section{Problems of Cleanliness issues:}

the lodging rooms should have clean, odor-free, eco-friendly and spacious conditions. This would help to drive more visitors to hotel. However, in most hotels that the study focused are lacks cleanliness. As soulayman my informant from culture and tourism department and head department of hotel supervision team said, there is frequent complain about the cleanliness of bed rooms, sheet, bath room and toilets. He also said that in most small hotels, basic facilities are not available such as dustbin, chair and table, floor mat, clean curtain, comfortable mattress and pillow. Even the room is very narrow and their walls are not painted annually and have unpleasant odor.

In addition to these, they have not fitness center, swimming pool, parking area, recreation activities, high speed internet connection, prompt response for their problems/complaints and quality service from trained employees are another problems that clearly observable in most sample hotels. Above all, lack of cleanliness is a major problem particularly in hotels that found in different districts of south wollo zone.

\section{Lack of proper transportation facility and lack of refreshing events and entertainment}

Hotels should be ready to provide transportation facility from all the major pick-up points of a city or from (airports, tourist destinations, etc) can make a huge improvement in hotel business management). But except three hotels in my study area the others cannot provide transport services to their customer indirectly this negatively affects the occupancy of their hotel.

Most of the tourists who stay came to hotel required refreshing events \& entertainment programs for getting relaxation, however as my informants assert there is no single hotels in my study hotels that carried out such 
types of activity, rather than rendering basic needs. But now a day's tourists are not satisfied solely by these services. Hence, it is better that some hotels are started to open an entertainment rooms such as cinema and standard night clubs so as to augment the satisfaction level of their customer and prolong their stay in their hotels.

\section{Conclusion and Recommendations}

Based on culture and tourism department report 9,064,675 domestic tourists visited the various tourist destinations of the zone from 2000 to 2009 i.e. since Ethiopian millennium to 2009. At the same time meager numbers of international tourists are visited these zone, 19,685 at the stated period. Hence the flow of domestic tourist surpass by millions than international tourists. There are different factors for the variation of these numbers and the first and for most reason is that the number of pilgrimage tourist that came to Gishen Debre kerba which nearly more than half a million tourist influxes into there.

Except Sunnyside hotel no one of them have swimming pool service, similarly except few like Golden gate, Hotel time, Sunnyside and Melbourne hotel almost the rest have not provide banquet hall and standard parking area. $84.1 \%$ of respondents show there is no much standard touristic hotel both in and Kombelcha towns and $51.4 \%$ of the respondents were complaining about the proper service delivery of hotels for international tourists

As the south wollo zone culture and tourism department report and my key informant shows, almost all employee in sample hotels are not professional even key hotel positions are run by families of hotel owners and the remaining vacant are held by non professionals. This factor is exacerbating the problem related with customer satisfaction. Regarding hotel development the result reveals that $66.4 \%$ of the respondents were agreed that hotel investment is growing in both Dessie and Kombolcha due to the lucrative nature of the industry and increment of the flow of visitors in the destination.

So as to mitigate problems related with hotels at Dessie and Kombolcha towns the following recommendations are forwarded based on the research finding

$>$ The regional government should invite more tourism investors to invest in the two towns particularly hotels investors;

$>$ Tourist attractions or destination should develop in appropriate manner and promote to the national and international tourists;

$>$ Problem related with hotel should solve especially the lack of trained staffs by giving on job training about how to handle customers and render services;

$>$ Culture and tourism department should work in collaboration with hotel owners, managers and in general with tourism stakeholders;

$>$ The zone and towns culture and tourism department should control the day today activities and qualities of currently functional hotels;

$>$ Wollo university should alleviate the knowledge gaps in related with hotel management and customer handling by giving continuous training to hotel owners, managers and direct customer contact personal besides;

$>$ Besides rendering basic needs, hotel should prepare special events and entertainment; provide transport services to their guests.

$>$ So as to mitigate staff turnover, hotels should pay appropriate salary and other related benefits

$>$ To become competitive enough with other hotels in the region as well as in the country, hotels that found in Dessie and Kombolcha should work to became star hotel by full filling the rules and regulation put by the government rather than posting fake star level on their billboard.

\section{Reference}

Anim O (2015), American Journal of Tourism Management Vol 4(3) “Assessing the Impacts of Hospitality Industry" in Enugu City, Nigeria

Alistair ,W.(2001), Hospitality, Leisure and Tourism: Understanding the Hospitality Consumer, Oxford, Great Britain

Amhara Region (2005) Ethiopia-Amhara National Regional State Tourist Attractions, Amhara National Regional State Tourism Commission.

Angelo, R. M. \& Vladimir, A (2001). Hospitality today: an introduction: Lansing, Michigan: Education Institute of the American Hotel \& Motel Lodging Association.

Benny C (2013), Tourism and Hospitality studies, Hong Kong

Bruce, P. (2006).Managing tourism and hospitality services: theory and international application, Cambridge, USA

Discover Amhara (2011) Tourist guide

Ebisa, C. and Andualem, H.(2013, “journal of Business management” (jbm), VOL. 1(2), JULY 2013, Hotel sector investment in Ethiopia

Gauravy .K (, 2014), "Challenges faced by the Hotel Industry: a review of Indian Scenario", IOSR Journal of 
Business and Management (IOSR-JBM) Volume 16, Issue 9 PP 69-73

Henok Mitiku (2005), "the Role of Private Sector in the Development of the Tourism Industry: The Case of Privately Owned Hotels in Addis Ababa", MA thesis, Addis Ababa University

John Wiley \& Sons, (2012), introduction to management in the hospitality sector, New Jersey

Ministry of Culture and Tourism (2011).Various Reports on Hotels and Tourism, Addis Ababa

Ministry of Culture and Tourism, (2009).Tourism Statistics Bulletin, Addis Ababa, Ethiopia

Muhamad S. (2014) Challenges to sustainable resort and hotel development in Malaysia,

Murray M. (2013) Tourism and hospitality studies: introduction to hospitality

Rose M. (2013), "Entrepreneurial Challenges Facing the Hospitality Industry in Kericho County-Kenya" Journal of Business and Economics, November 2013, Volume 4

World Bank, (2005). Country in brief - Ethiopia (http://go.worldbank.org/WA1RL12OL0).

\section{Unpublished sources}

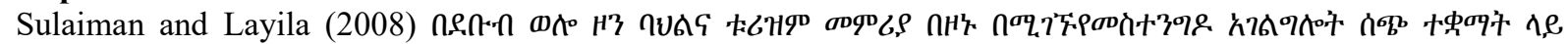

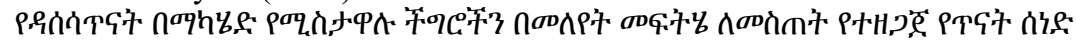

South wollo zone culture and tourism report of 2009E.C.

Desseie Town Culture and tourism report of 2009E.C. 